\title{
CHRONIC INFLAMMATORY DEMYELINATING POLYRADICULONEUROPATHY ASSOCIATED WITH SYSTEMIC LUPUS ERYTHEMATOSUS
}

Paulo Rogério Julio ${ }^{1}$, Mateus De Miranda Moura Cortês ${ }^{1}$, Juliana Zonzini Gaino ${ }^{1}$, Marcondes Cavalcante França Junior ${ }^{1}$, Lilian Tereza Lavras Costallat ${ }^{1}$, Simone Appenzeller ${ }^{1, \star}$

1.Universidade Estadual de Campinas, Campinas (SP), Brazil.

${ }^{\star}$ Corresponding author: appenzellersimone@gmail.com

\section{BACKGROUND}

Chronic inflammatory demyelinating polyradiculoneuropathy (CIDP) is an uncommon subtype of peripheral neuropathy (PN) and especially when associated with systemic lupus erythematosus (SLE). There are few reports characterizing PN-associated to SLE, in particular CIDP. This study reviewed the frequency and profile of SLE-related CIDP in our SLE cohort.

\section{CASE REPORT}

We reviewed our database to identify patients with CIDP and SLE. Clinical, laboratory and treatment features were described. We identified three patients with SLE and CIDP in our cohort of 1,349 patients with SLE (0.2\%). All patients were female, aged between 30 and 44 years and 2 (66.7\%) had active disease in other organs

\section{CONCLUSION}

Although rare, CIDP has increased frequency in SLE. Women, age and SLE disease activity should rise suspicion of an underlying autoimmune disease. 